\title{
Labour Pain and Satisfaction of Primipara Assume Upright versus Recumbent Positions during First Stage of Labour
}

\author{
"Mona Youssef Al-Seady ${ }^{1}$, Eman A. Fadel ${ }^{1}$, Alaa Mohamed El-Gohary ${ }^{2}$, \\ Tyseer Marzouk ${ }^{1}$ \\ ${ }^{1}$ Woman's Health and Midwifery Department, Faculty of Nursing-Mansoura University, Egypt \\ ${ }^{2}$ Obstetrics and Gynecology Department, Faculty of Medicine-Mansoura University, Egypt \\ Corresponding Author: Mona Yousef
}

\begin{abstract}
This study aimed to compare labour pain and satisfaction of primipara assume upright versus recumbent positions during first stage of labour.

Subjects and method: A quasi-experimental research design was used at the Labour and delivery room of Mansoura University Hospital. A purposive sample of 134 parturient women in $1^{\text {st }}$ stage of labour enrolled in this study, they divided into two groups; study group (n=67) assumed one of upright positions as walking, sitting, standing, kneeling, and squatting during first stage of labour and control group (n=67) assumed one of recumbent positions as supine, semi-recumbent and lateral position during the same stage. Three tools were used for data collection; a structured interview questionnaire, Visual Analogue Scale and maternal satisfaction with assumed position questionnaire.

Results: parturient women who were assumed upright positions had lower labour pain and higher satisfaction scores compared to those assumed recumbent positions $(p=<0.001)$.

Conclusion and recommendations: upright position was an effective method in reducing labour pain and improving parturient women's satisfaction with assumed position. Thus, it is recommended to encourage parturient women to maintain upright positions during first stage of labour.
\end{abstract}

Keywords: Labour, first stage, upright position, recumbent position.

Date of Submission: 05-07-2017

Date of acceptance: 17-07-2017

\section{Introduction}

Pregnancy and childbirth are unique processes for women. They are important periods in woman's life. It ends with labour which is the most wonderful moment in women's life, highly joyful experience and celebrated event to their families (Carol 2012, Iravani et al. 2015, Azibaben et al. 2012).

The process of having a baby occurs in several stages over many hours or even few days from early labour to deliver the baby and placenta. For advancing of the process of normal labour, the woman has to pass four stages of labour (Hodnett et al. 2013). First stage of labour is the longest one. It lasts about 12 to 16 hours for primipara and about 6 to 8 hours for multipara (White, Duncan, \& Baumle, 2011). First stage of labour consisted of three phases; latent, active and transitional phase (Simpson \& O'Brien Abel 2014). Parturient woman admitted to hospital for labour while in active phase where contractions become longer and more frequent (Davidson et al. 2015).

Most of parturient women feel shaky, shivery, sick and impatient with everyone at time of uterine contraction. Parturient woman's right for feeling labour pain should be respected (Downe \& Marshall 2014). Pleasant childbirth is every mother's wish and a positive birth experience is associated with higher self-reported satisfaction score (Baldisserotto, Filha \& da Gama, 2016).

Once a woman approaching labour and become hospitalized, health care providers let her to assume supine position to be confined to the bed. Not all care providers will allow free ambulation in labour, and limit positions to labour on the bed alone (Thies-Lagergren, et al. 2013). Since parturient woman's position influences woman's anatomic and physiologic accommodation to labour, various positions can be assumed during first stage of labour such as, standing, walking, kneeling foreword with support, and sitting position. It results in relieving fatigue, increasing maternal comfort, increasing frequency and intensity of uterine contractions and decreasing need for analgesia (Moghadam et al. 2013).

A previous study has suggested that if parturient women lie on backs, this may have adverse effects on uterine contractions and impede progress in labour. Uterine contraction is potentially painful, and prolonged labour can be an overwhelming and exhausting process resulting in an increased need for medical intervention (Lawrence, Lewis, Hofmeyr, \& Styles, 2013). On the other hand, evidence suggests that changing position and assuming upright position in first stage of labour increases effectiveness of contractions and help feeling more 
comfortable, reduces the pain, reduce the length of labour and increase mother satisfaction (Hollins Martin \& Martin 2013). Thus, the present study aims to compare labour pain and satisfaction of primipara assume upright versus recumbent position during first stage of labour.

\subsection{Significance of the study}

Form of support and care provided to labouring woman is a very important aspect on their comfort. It can negatively or positively affecting the woman's and her family experiences of labour. There is a lack of studies which address the comparison of two positions during the active phase of first stage of labour on labour outcomes at Mansoura University Hospitals. Thus, the current study aims to compare labour pain and satisfaction of primipara assume upright versus recumbent position during first stage of labour.

\subsection{Aim of this study}

This study aimed to compare labour pain and satisfaction of primipara assume upright versus recumbent position during first stage of labour.

1.3 Study hypothesis "Parturient primipara who assumes upright position during first stage of labour report lower labour pain and higher satisfaction with this position compared to those who assume recumbent position".

\subsection{Research Design}

\section{Subjects And Method}

A quasi-experimental research design was used in this study to compare labour pain and satisfaction of primipara assume upright versus recumbent position during first stage of labour.

\subsection{Study setting}

This study was conducted at Labour and delivery unit of Mansoura University Hospital. Labour and delivery unit is located at first floor of the main hospital's building with a capacity of 19 beds. It is alienated into four sections: $1^{\text {st }}$ section is the labour progress follow-up room ( 8 beds), $2^{\text {nd }}$ section is the delivery room which includes 2 delivery tables and enclosed small unit for immediate baby care with a warmer device and suction machine, $3^{\text {rd }}$ section is a 4 bed observation room for monitoring high risk cases like eclampsia, and finally postnatal room with 5 beds for observation of postnatal changes. In addition to check-up room with 2 trolleys.

\subsection{Sampling}

Primipara parturient women who admitted to Labour and delivery unit; in early active phase of $1^{\text {st }}$ stage of labour (i.e., from 4 to $6 \mathrm{~cm}$ cervical dilation), between October 2016 to March 2017 was the target sample in this study if fulfilled the following criteria:

- $\quad$ Aged between 20-35 years.

- Have a single, viable, and term ( $\geq 37$ weeks) fetus in occipto anterior position.

- Free from medical or obstetrical disorders that may interrupt labour progress.

Inclusive sample was recruited by a purposive sampling technique from the target population based on meeting eligibility criteria and by substitution in this formula: $\quad n=\left[\left(\mathbf{Z}_{\alpha / 2}+\mathbf{Z}_{\beta}\right)^{2} \times\left\{\mathbf{2}(\mathbf{S D})^{2}\right\}\right] /(\mathbf{d})^{2}$, Where, $n$ is the sample size required per each group, $d$ is the accepted difference between the two groups from a previous study Kumud et al., 2013, SD is standard deviation, Z $\alpha / 2$ depends on level of significance, for $5 \%$ this is 1.96 , and $Z \beta$ depends on power, for $80 \%$ this is 0.84 . Therefore, $n=[(1.96+0.84) 2 \times\{2(103.1) 2\}] /(50) 2=134$

Total sample $(\mathrm{n}=134)$ was divided into two group:

1. Study group $(n=67)$ : was the intervention group and assumed one of upright positions during first stage of labour, defined as walking and upright non-walking (i.e., sitting, standing, kneeling, squatting).

2. Control group $(n=67)$ : was assumed one of the recumbent positions during the same labour stage (i.e., supine, semi-recumbent, lateral position).

\subsection{Data Collection Tools}

Required data were collected by using three tools; specifically, structured interviewing questionnaire, Visual Analogue Scale-Pain, and maternal satisfaction with assumed position was assessed by a developed twoitem questionnaire.

\section{Tool I: Structured Interviewing Questionnaire}

It was designed by the researcher after reviewing the related literature and was consisted of two parts.

Part 1. Participants' sociodemographic characteristics (e.g., age, educational level, occupation, residence).

Part 2. Participants' current Obstetric data (e.g., gestation weeks, state of membranes, Bishop Score).

Tool 2. Visual Analogue Scale (VAS-pain)

It was established by Lundeberg et al., 2001 to measure pain intensity. It is a horizontal line marked in centimeters that ranges from 0 to 100 , where 0 means no pain and 100 indicates worst possible pain. 
Respondents were asked to refer to the exact point representing level of experienced pain. Labour pain scores were determined by measuring the distance from 0 to the marked pain location.

Tool 3. Maternal satisfaction with assumed position

It was assessed by a developed two-item questionnaire. Each participant was asked to respond to two questions: 1) Are you satisfied with your assumed position during $1^{\text {st }}$ stage of labour? 2) Do you prefer assigned position in future deliveries? Their responses were recorded as either yes or no.

\subsection{Validity of Data Collection Tools}

In this study, the structured interview questionnaire was developed by the researcher thus it was subjected for review by a panel of five expertise in Maternity and Gynecology of Nursing to test its validity. Based on their suggestions minor modifications were done. The VAS-Pain is a standardized tool. Its validity was tested in previous studies.

\subsection{Ethical considerations}

1. Ethical clearance was obtained from the Research Ethics Committee of Nursing Faculty, Mansoura University.

2. An informed consent was obtained from each participant after clarifying study nature.

3. Confidentiality of collected data was maintained.

4. The investigator was emphasized that participation is voluntary and each participant has a right to withdraw from the study at any time.

\subsection{Field work}

Field work began on October 2016 and finished on March 2017. It was carried out through three phases; preparatory phase, implementation phase, and outcome assessment phase.

\section{Preparatory phase}

During the preparatory phase; the researcher introduced official letters from Faculty of Nursing, Mansoura University to the director of Mansoura University Hospitals and Head of Obstetrics and Gynecology Department to obtain official permission to conduct the study after clarifying its aim. Tools of data collection were prepared, its validity was checked. A pilot study was carried out on $10 \%$ of predetermined sample $(n=14$ labouring women) to ascertain the applicability and clarity of the tools. This phase took about one month from the study period.

\section{Implementation phase}

During this phase, both groups were subjected to the same management of first stage of labour according to the followed guidelines in study setting except for assumed position during $1^{\text {st }}$ stage of labour. Eligible parturients were enrolled in this study by giving their written consent. The researcher was attended the study setting three days weekly from 9 am to $2 \mathrm{pm}$ to collect the required sample. Assessment was done by individual interview with potential participants. First 67 eligible parturients were assigned for control group. However, second 67 were subjected to intervention and represent the study group. On admission, Bishop Score and membranes state were assessed. Parturient women with ruptured membranes and non-engaged head not allowed walking to avoid cord prolapse. Parturients were monitored for labour progress using the partograph. Control group participants were assumed one of recumbent positions during $1^{\text {st }}$ stage of labour (i.e., supine, semi-recumbent, lateral). Supine position indicates to that parturient woman is lying flat on her back in the bed. Semi-recumbent means that parturient woman is lying on her back at an angle up to 45 degree, while lateral position refers to that parturient woman is lying on her side. Maintaining position was ascertained by asking participants to assume assigned position for 15-20 every hour. Study group participants were assumed one of upright positions during the same stage (i.e., walking and upright non-walking as sitting, standing, kneeling, or squatting). Walking out of bed and advised her to return to bed when intervention needed, sitting position was assumed on the bed or on chair with back support, standing position was achieved by herself or with support on wall. Each participant was assumed such position for 15-20 minutes every one hour according to her comfort and in between they were allowed to lie down on bed for 10-15 minutes. Participants were asked to return in bed in case of fetal distress on checking fetal heart rate or if amniotic fluid was stained with blood or meconium.

\section{Assessment of study outcomes}

Both groups were monitored during $1^{\text {st }}$ stage of labour and then outcomes was assessed and recorded for further statistical analysis. VAS-Pain was used to identify intensity of labour pain, while maternal satisfaction with assumed position and their preferences to this position in future deliveries were assessed by asking participants two questions: 1) Are you satisfied with your assumed position during $1^{\text {st }}$ stage of labour? 2) Do you prefer assigned position in future deliveries? Their responses were recorded as either yes or no. 


\subsection{Statistical analysis}

Collected data were coded, computed and statistically analyzed using SPSS (Statistical Package of Social Sciences) version 20. Qualitative data were presented in tables as frequency and percentage, while quantitative data were presented as Mean $\pm \mathrm{SD}$. Comparing the qualitative variables was done using Chi square $\left(\mathrm{X}^{2}\right)$, while comparing quantitative variables in two groups was done using test, and more than two groups using one way a nova test. The correlation of two quantitative variables was done using Pearson's correlation coefficient (r). The difference was considered significant if $\mathrm{P} \leq 0.05$.

\section{Results}

\section{General characteristics of the study and control groups}

Table 1 shows distribution of socio-demographic characteristics of study and control groups. It shows that mean ages of both groups were almost identical ( $25.9 \pm 3.9$ vs. $26.3 \pm 4.2$ years) in study and control groups respectively, with more than half of both groups aged 21 to 26 years. Around three quarters (74.6\% vs. $79.1 \%$ respectively) of the study and control groups belonged to rural origin. Secondary education was the highly distributed educational level $(56.7 \%$ vs. $65.7 \%)$ respectively in study and control groups. Housewives were more than working $(61.2 \%$ and $73.1 \%$ respectively) in study group and control groups. There were no statistically significant differences regarding age, residence, level of education and occupation in both groups ( $\mathrm{p}$ $>0.05$ ).

Table 2 clarifies findings of vaginal examination of study and control groups on admission. It shows that slightly more than three quarters and slightly more than two thirds $(76.1 \%$ and $67.2 \%)$ respectively in the study and control groups had bloody vaginal discharge. Most of parturient in study group and majority of control group had intact membranes on admission (94\% and 89.6\% respectively). Mean Bishop Scores were almost similar in the study and control groups on admission (10.4 \pm 1.0 vs. $8.7 \pm 1.4$ respectively). There were no statistically significant differences between study and control groups regarding vaginal discharge, condition of membranes and bishop score on admission $\left(X^{2}=1.53,0.89,7.92\right.$ respectively; \& $\left.p>0.05\right)$.

\section{Intensity of labour pain in study and control groups}

Table 3 shows intensity of labour pain in study and control groups after assuming the assigned positions. It is clear from this table that slightly more than two fifth $(41.8 \%)$ of participants in the study group show high abdominal pain level compared to more than half of the control group (53.7\%) during active acceleration phase. During active deceleration phase, less than half of study group (46.3\%) compared to almost two thirds of the control group (64.2\%) showed high pain level in the abdomen. However, the highest level of low back pain was the moderate level (56.7\%) among the study group, while high level of low back pain affected the highest percentage in the control group (47.8\%) during active acceleration phase. With increasing cervical dilation to 8 $10 \mathrm{~cm}$, very high level of low back pain was the highest in the control group (52.2\%) compared to only $28.4 \%$ in study group. Differences observed for intensity of labour pain; either abdominal or low back, during both phases of the active phase of first stage of labour were highly statistically significant $(\mathrm{p}<0.001)$.

\section{Mother's satisfaction and preferences to assume same positions in future deliveries}

Table 4 shows mother's satisfaction by the assumed position in study and control groups. It shows that more than three quarters $(79.1 \%)$ of study group were satisfied with upright position compared to slightly less than one third $(33.1 \%)$ of control group were satisfied with recumbent position. Differences observed were highly statistically significant $(\mathrm{p}<0.001)$.

Figure 3 illustrates maternal position's preferences of same position in future delivery by the study group. It reveals that study group were more anticipated $(77.6 \%$ ) to assume upright position in future delivery compared to only $32.8 \%$ in control group who preferred to assume recumbent position in future delivery. Differences observed between study and control groups were statistically significant.

Table 1. Distribution of socio-demographics of the study and control groups $(n=134)$

\begin{tabular}{|c|c|c|c|c|c|c|}
\hline \multirow{2}{*}{$\begin{array}{c}\text { Socio-demographic } \\
\text { Variables }\end{array}$} & \multicolumn{2}{|c|}{ Study group $(n=67)$} & \multicolumn{2}{|c|}{ Control group $(n=67)$} & \multicolumn{2}{|c|}{ Chi square test } \\
\hline & $\mathbf{N}$ & $\%$ & $\mathbf{N}$ & $\%$ & $\mathbf{X}^{2}$ & $\mathbf{P}$ \\
\hline \multicolumn{7}{|l|}{ Age (years) } \\
\hline $20-$ & 39 & $58.2 \%$ & 36 & $53.7 \%$ & & \\
\hline $26-$ & 18 & $26.9 \%$ & 20 & $29.9 \%$ & & \\
\hline $30-35$ & 10 & $14.9 \%$ & 11 & $16.4 \%$ & 0.27 & 0.872 \\
\hline Mean \pm SD & $25.9 \pm 3.9$ & & $26.3 \pm 4.2$ & & 0.54 & 0.594 \\
\hline \multicolumn{7}{|l|}{ Residence } \\
\hline Rural & 50 & $74.6 \%$ & 53 & $79.1 \%$ & & \\
\hline Urban & 17 & $25.4 \%$ & 14 & $20.9 \%$ & 0.38 & 0.539 \\
\hline \multicolumn{7}{|l|}{ Level of education } \\
\hline Illiterate & 4 & $6.0 \%$ & 3 & $4.5 \%$ & & \\
\hline Read and Write & 11 & $16.4 \%$ & 5 & $7.5 \%$ & & \\
\hline Secondary & 38 & $56.7 \%$ & 44 & $65.7 \%$ & & \\
\hline
\end{tabular}




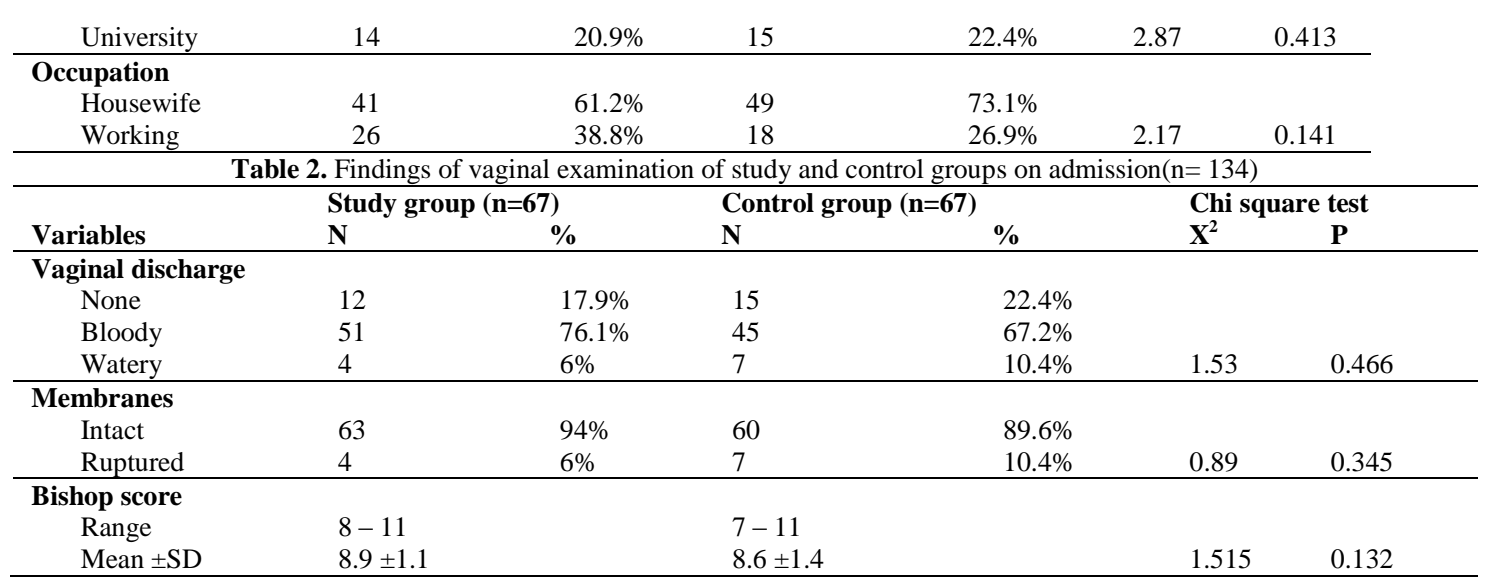

Table 3. Intensity of labour pain in study and control groups after assuming assigned positions $(n=134)$

\begin{tabular}{|c|c|c|c|c|c|c|}
\hline \multirow[t]{2}{*}{ Time period } & \multicolumn{2}{|c|}{ Study group $(n=67)$} & \multicolumn{2}{|c|}{ Control group $(n=67)$} & \multicolumn{2}{|c|}{ Chi square test } \\
\hline & $\mathbf{n}$ & $\%$ & $\mathbf{N}$ & $\%$ & $\mathbf{X}^{2}$ & $\mathbf{P}$ \\
\hline \multicolumn{7}{|c|}{ Abdominal pain during active acceleration phase $(4-7 \mathrm{~cm}$ cervical dilation $)$} \\
\hline Moderate & 39 & $58.2 \%$ & 19 & $28.4 \%$ & & \\
\hline High & 28 & $41.8 \%$ & 36 & $53.7 \%$ & & \\
\hline Very high & 0 & $0.0 \%$ & 12 & $17.9 \%$ & 19.89 & $<0.001$ \\
\hline \multicolumn{7}{|c|}{ Abdominal pain during active deceleration phase $(8-10 \mathrm{~cm}$ cervical dilation) } \\
\hline Moderate & 27 & $40.3 \%$ & 4 & $5.9 \%$ & & \\
\hline High & 31 & $46.3 \%$ & 43 & $64.2 \%$ & & \\
\hline Very high & 9 & $13.4 \%$ & 20 & $29.9 \%$ & 23.18 & $<0.001$ \\
\hline \multicolumn{7}{|c|}{ Low back pain during active acceleration phase $(4-7 \mathrm{~cm}$ cervical dilation) } \\
\hline Moderate & 38 & $56.7 \%$ & 19 & $28.4 \%$ & & \\
\hline High & 28 & $41.8 \%$ & 32 & $47.8 \%$ & & \\
\hline Very high & 1 & $1.5 \%$ & 16 & $23.9 \%$ & 19.82 & $<0.001$ \\
\hline \multicolumn{7}{|c|}{ Low back pain during active deceleration phase $(8-10 \mathrm{~cm}$ cervical dilation) } \\
\hline Moderate & 29 & $43.3 \%$ & 7 & $10.4 \%$ & & \\
\hline High & 19 & $28.4 \%$ & 25 & $37.3 \%$ & & \\
\hline Very high & 19 & $28.4 \%$ & 35 & $52.2 \%$ & 19.00 & $<0.001$ \\
\hline
\end{tabular}

Table 4. Mother's satisfaction by the assumed position in study and control groups $(\mathrm{n}=134)$

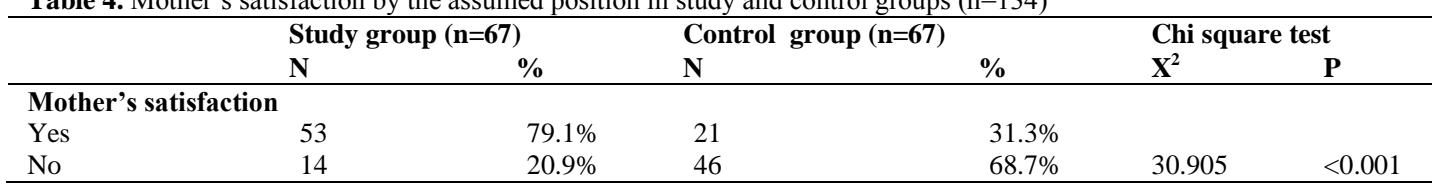

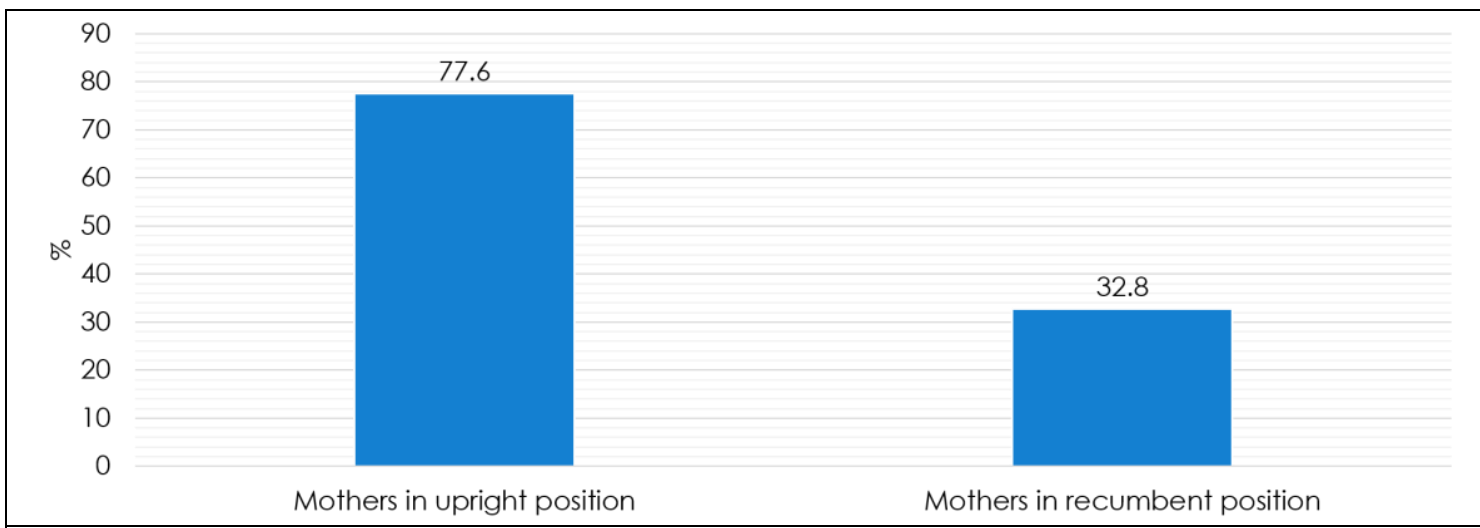

Figure 1. Maternal position's preferences of same position in future delivery by the study group $(\mathrm{n}=134)$

\section{Discussion}

The present study aimed to compare labour pain and satisfaction of primipara assume upright versus recumbent position during first stage of labour. This aim was achieved through the present study findings which revealed lower labour pain and higher satisfaction levels among parturients assumed upright than those assumed recumbent position. Labour pain during active phase of labour was evaluated in this study. By dichotomizing the active phase of first stage of labour into active acceleration phase $(4-7 \mathrm{~cm}$ cervical dilation) and active 
deceleration phase $(8-10 \mathrm{~cm}$ cervical dilation), the current study results showed that parturient mothers in upright positions group recorded less abdominal and low back pain during active phase of labour. Maintaining upright position reduced both abdominal and low back pain intensity from very high to high, and from high to moderate levels. Therefore, the study hypothesis "Parturient primipara who assumes upright position during first stage of labour report lower labour pain and higher satisfaction with this position compared to those who assumed recumbent position" is accepted.

These findings are in the path of a clinical trial that was conducted on a purposive sample of 400 Iranian pregnant mothers (Rana 2012). Parturients were encouraged to change between supine and sitting positions alternatively, each for 15 minutes. Rana assessed labour pain levels during assuming each position and observed lower pain intensity during sitting position compared to recumbent position. Also, sitting position decreased pain level from moderate to mild, and from severe to moderate one. In another way, Davim et al., 2007 investigated effect of changing position from supine to sitting; as a non-pharmacological method, on reducing labour pain strength and concluded that such method is applicable and appropriate in reducing pain level. The researcher may attribute cause of lower pain level in upright positions to the notion that in these positions there is no pressure against sacroiliac joints and the nerves that are responsible about pain transmission.

However, Judie and colleagues 2015 studied effectiveness of left lateral positions versus upright positions on labour pain for a purposive sample of sixty Indian parturient mothers in their first stage of labour and reported that participants had less pain with assuming left lateral position compared to upright position. This result may be related to the difference of the studied sample either for the size or for the parity number.

Relating to mother's satisfaction with assumed positions, the study findings show that majority of study group was satisfied with assuming upright position compared to almost one third of control group was satisfied with recumbent position. In addition, current study results revealed that more than three quarters in upright group were more anticipated to assume same position in future deliveries compared to slightly less than one third in control group who preferred to assume recumbent position in the future. Thus, the $2^{\text {nd }}$ study hypothesis was accepted "Parturient primiparas who assume upright position report higher satisfaction and preferences for such position compared to those who assumed recumbent position".

This finding agreed with that of Mathew and colleagues (2012). They were found that women who encouraged to walk were more comfortable and satisfied, while it was contradicted with Hodnett et al., (2011) finding which indicated that parturient mothers who were assumed side lying or lying on back were more satisfied with this position in first stage of labour. Such finding may be related to rapid progress of labour, experiencing less labour pain, or attaining vaginal deliveries.

In conclusion, this study revealed that assuming upright position during first stage of labour results in advantages for the parturient primipara woman by decreasing level of abdominal and low back pain and increasing maternal satisfaction with their labour experience. Thus, maintaining upright positions as walking and upright non-walking, like sitting, standing, kneeling, and squatting position is recommended during first stage of labour.

\section{References}

[1] Azibaben, I., Olayinka, A., Mombel, M., \& Achi, O. (2012). Perceived effects of midwives attitudes toward women in labour in Bayelsa State, Nigeria. Archives Applied Sci Res, 4(2), 960-964.

[2] Baldisserotto, M., Filha, M., \& da Gama, S., (2016). Good practices according to WHO's recommendation for normal labour and birth and women's assessment of the care received: the "birth in Brazil" national research study, 2011/2012. Reproductive Health, 13(3), 124-128.

[3] Carol, J., Green. (2012). Maternal Newborn Nursing Care Plans (3th ed.). United State of America: Jones and Bartlett Learning, Lippincott Co.

[4] Davidson, M., London, M., \& Ladewig, P., (2015). Olds' maternal-newborn nursing \& women's health across the lifespan: Pearson.

[5] Downe, S., \& Marshall, J., (2014). Physiology and care during the transition and second stage phases of labour. In J. E. a. R. Marshall, Maureen D, (eds.) (Ed.), Myles textbook for midwives. 16th ed. (pp. 367-393.). Edinburgh, U.K. : Churchill Livingstone: Nursing and midwifery.

[6] Hodnett, E., Gates, S., Hofmeyr, G., \& Sakala, C., \& Weston, J., (2011). Continuous support for women during childbirth The Cochrane Database of Systematic Reviews (2): John Wiley \& Sons, Ltd.

[7] Hollins Martin, C., \& Martin, C., (2013). A narrative review of maternal physical activity during labour and its effects upon length of first stage. Complementary Therapies in Clinical Practice, 19(1), 44-49.

[8] Iravani, M., Zarean, E., Janghorbani, M., \& Bahrami, M. (2015). Women's needs and expectations during normal labour and delivery. Journal of Nursing and Midwifery Research, 4, 6.

[9] Judie, A., \& Sophia, C. M. (2015). A Comparative Study To Assess The Effectiveness Of Left Lateral Position Vs. Upright Position On Fetal Heart Rate And Labour Pain Among Parturient Mothers In I Stage Of Labour At Government Hospital. Vellore Research \& Reviews: Journal of Nursing \& Health Sciences, 1(3), 34-40.

[10] Lawrence, A., Lewis, L., Hofmeyr, G., \& Styles, C., (2013). Maternal positions and mobility during first stage labour. The Cochrane Library.

[11] Lundeberg, T., et al (2001): Reliability and responsiveness of three different pain assessment. Journal of Rehabilitation Medicine; Nov. 33:279-83. 
[12] Mathew, A., Nayak, S., \& Vandana, K., (2012). A Comparative Study On Effect Of Ambulation And Birthing Ball On Maternal And Newborn Outcome Among Primigravida Mothers In Selected Hospitals In Mangalore. Nitte University Journal of Health Science, 2(2), 2249-7110.

[13] Moghadam, A., Delpisheh, A., Rezaeian, M., \& Khosravi, A. (2013). Factors Affecting the Labour : A Review Article. Biomedical \& Pharmacology Journal, 6(2), 161-167.

[14] Rana, D., (2012). The Relationship Between A Woman's Position During Labour And The Level Of Feeling Pain In The Active Phase Of Labour, Life Science Journal 9(4), 5-8.

[15] simpson, K., \& O'Brien, A. (2014). labour and birth.AWHONN peinatal nursing (4th ed.) 343-444. philadelphia: lippincott wiliams \& wilkins.

[16] Thies-Lagergren, L., Hildingsson, I., Christensson, K., \& Kvist, L. J. (2013). Who decides the position for birth? A follow-up study of a randomised controlled trial. Women and Birth, 26(4), e99-e104.

[17] White, L., Duncan, G. \& Baumle, W. 2011. Foundations of Maternal and Pediatric Nursing,3rd ed. United States of America, Delmar Cengage Learning Co, 72-79. 